\title{
A Review on Broker Based Cloud Service Model
}

\author{
Nagarajan Rajganesh ${ }^{1}$ and Thirunavukarasu Ramkumar ${ }^{2}$ \\ ${ }^{1}$ Department of Information Technology, A. V. C. College of Engineering, Mayiladuthurai, Tamilnadu, India \\ ${ }^{2}$ School of Information Technology and Engineering, VIT University, Vellore, Tamilnadu, India
}

Cloud computing emerged as a utility oriented computing that facilitates resource sharing under pay-asyou-go model. Nowadays, cloud offerings are not limited to range of services and anything can be shared as a service through the Internet. In this work, a detailed literature survey with respect to cloud service discovery and composition has been accounted. A proposed architecture with the inclusion of cloud broker is presented in our work. It focuses the importance of suitable service selection and its ranking towards fulfilling the customer's service requirements. The proposed cloud broker advocates techniques such as reasoning and decision making capabilities for the improved cloud service selection and composition.

ACM CCS (2012) Classification: Computer systems organization $\rightarrow$ Architectures $\rightarrow$ Distributed architectures $\rightarrow$ Cloud computing

Keywords: cloud computing, service discovery, service delivery, cloud broker

\section{Introduction}

Due to the versatile nature of requirements raised by information technology stakeholders, there is a potential demand for computational resources, software platforms and business services. Since the usage of such resources are not frequent and the users consume the services only during their requirement, a computing environment that supports on-demand, utility-oriented is prompted and the same has been offered by a paradigm named cloud computing [1]. With cloud computing, required services like computational resources which include machine, software and infrastructure can be acquired and deployed by the users with a less investment. In this way, cloud computing promotes the computational environment as a public utility where certain kinds of services have been offered free of cost while others charge for the service provided, where the cost is proportionate to the utilization of the services. Cloud computing offers to the Internet users various service models [2] at different levels of abstraction, broadly termed as Software as a Service (SaaS), Platform as a Service (PaaS) and Infrastructure as a Service (IaaS), as shown in Figure 1.

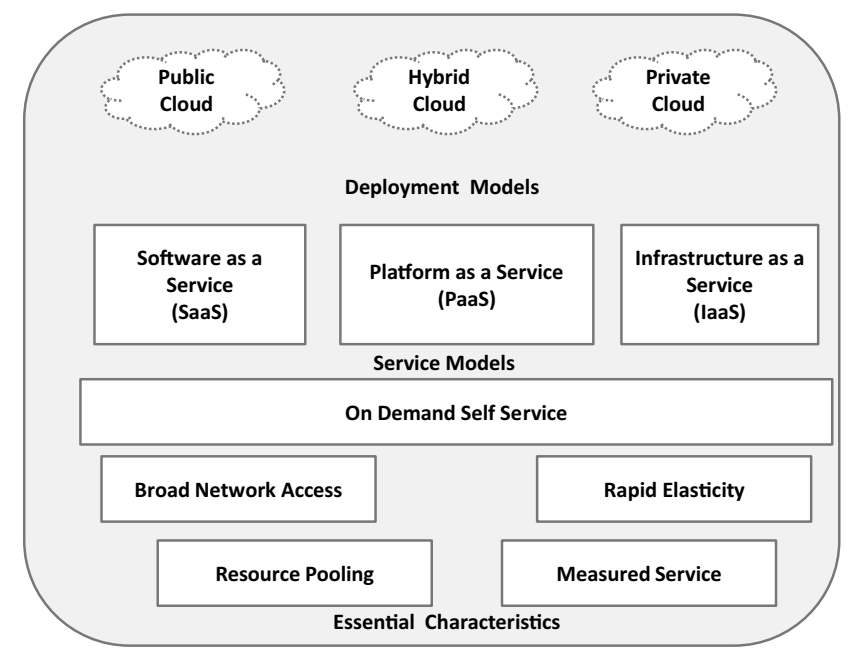

Figure 1. A typical cloud computing model.

The Software as a Service (SaaS) model allows the consumers to avail the predefined compound functionalities through the Internet from the cloud service provider. The objective here is to deliver the application services to the users as per their requirements. Hence, the end users need not worry about the issues such as installation and future maintenance overheads. 
The second service called Platform as a Service (PaaS) is implausible model for offering to the cloud user the computing platform that includes operating systems, program developing environment, web servers and database systems. From this model, a platform resource can be shared and re-used among the consumers. The third service namely, Infrastructure as a Service (IaaS) meant for delivering the cloud computing infrastructure such as physical computers, storage, network and related resources for the deployment of user operating system, application software. Through this, the users can own the peripherals and can configure them as per their wish. Besides the above three services, a cloud user can avail any sort of services, deemed to be called as Anything as a Service (XaaS). In short, the major offering of the cloud is classified as [3] computational services, storage and operating systems (OS) level services (scheduling and management of tasks), computing platforms (for designing and developing applications), provision of user access interface, web APIs, a framework for programming. On the basis of the nature of consumption, the user groups [4] are labeled as follows: public cloud, where the cloud services are offered as the open access for the general public; private cloud, where the cloud services are offered for the exclusive use of a single person or an organization which comprises a lot of business units. A hybrid cloud contains a combination of both public and private type clouds.

Though cloud computing allows the cloud users to avail such kind of services from multiple cloud vendors, there is a blind gap that exists between the above stakeholders which results in the delivery of unsuitable services to the user even though the requirements are clearly stated. Such circumstances attract the need for an intermediate service layer that bridges both parties for effective service consumption/delivery. It prompts us to develop a proposal including a cloud broker in the existing cloud model to enhance the functionalities of cloud life cycle phases such as requirements gathering, service discovery, aggregation and delivery of cloud services.

The organization of the paper has been structured as follows: Section 2 presents a broad survey of the related works in the cloud service discovery phase and delivery of services. An exhaustive literature survey has been made and various research efforts along with their significant outcomes are analyzed and presented. The proposed architecture with the inclusion of cloud broker is introduced in Section 3. The desirable functionalities of the proposed broker are also elaborated in the same section. The concluding remarks with further research directions are accounted in Section 4.

\section{Background and Related Works}

Cloud computing allows the users to find out the required services and make use of them. For that, cloud has the flexibility in its nature to allow the user to perform the service discovery before the aggregation process. The user/provider is responsible for coordinating the process in order to avail/provide the required services. In this section, the important research attempts along with their findings with respect to service discovery, composition and delivery of services are presented.

\subsection{Service Discovery in Cloud Environment}

In cloud computing, service discovery [5] leads to finding a suitable cloud service for the posted requirements, which essentially refers to the discovery of service description. Service description is a specification which covers both the functional and non-functional capabilities and in terms of a service [6]. The description must be clearly defined about the functioning of the service and it has to motivate the user to prefer them. Also, the descriptions should be available for the users side when they are surfing through the Internet. From the below said related works, we have identified the methodologies followed to discover the cloud services and also to understand the issues of the existing models in the service discovery phase.

Peng [7] attributed the concept of K-means clustering algorithm for generating feature vector based service description. His proposal described the services by means of feature vector through Principle Component Analysis (PCA), clustered the services by means of K-means clustering algorithm and identified the targeted services through matchmaking principle. The 
concept of clustering [8] is one of the promising methods for handling unsupervised data and purposely used in the domain of machine learning. But, the authors failed to include more classifying methodologies for the finding of best match.

Kang and Sim [9]-[11] proposed their work to discover the services based on ontology. The ontology for the discovery of services [12] is constructed using the reasoning based techniques which are a part of artificial intelligence. They have developed a discovery system based on ontology reasoning for evaluating and matching the service request raised by the cloud user. The construction of ontology with respect to the customer input specification simplifies the search process and offers the most suitable services to them. Further, the ontology construction has been performed by the software entity named Agent.

Mastroianni and Papuzzo [13] were focused on clustering service and cluster service descriptors on the basis of co-use frequencies of corresponding services. The services that are executed in the same workflow are grouped together and placed into the specified network location. By this scattering progress, the co-occurrences of services, response-time, bandwidth and load are considerably reduced. This paper gives an overview about the functioning of mobile agents in the area of service discovery.

Choi and Jeong [14] proposed a system with a pairwise comparison and an eigen-vector concept for calculating the priority information of the posted consumer's requirements. This approach introduced the broker-based evaluation system. The proposed model aimed to collect the data matching the consumer's input, perform the pair-wise comparison, and rank the services to determine the quality of service. It is noticed that the proposed broker does not have the appropriate decision making capability to carry out the service selection process. Without the idea of independent thinking capability of the broker architecture, we cannot prefer this for the federated cloud service discovery.

Ronald et al. [15] proposed a system to look out the best desirable services that fit the user's requirements by the lexicographical preferences. Accordingly, a single threshold value is being used to represent user's satisfaction level with the boundary values of acceptable and unacceptable attributes. It has been observed that certain kinds of inconsistency may arise due to improper decision of the user. Besides, their work fails to address the issue of choosing a proper method for attaining the threshold objectively.

Talal et al. [16] introduced a model named Cloud Service Crawler Engine (CSCE), a cloud service ontology based on cloud computing standard developed by National Institute of Standards and Technology (NIST). They have performed a layered approach for the task of service discovery. Accordingly, a cloud crawler has been constructed on the basis of ontology to automatically discover, validate, and categorize cloud services. From the constructed ontology, a seedcollector finds out the appropriate links for the services in the cloud environment and then filters the exact links which best fit with the customer's needs. From the understandings, we plan to develop our broker with the reasoning concept of artificial intelligence to think independently for performing service discovery in a federated cloud environment.

Souza and Rabelo [17] contributed a service discovery model based on two phase mechanism namely, off-line and on-line. In the offline phase, a business process list has been constructed to identify the business requirement. During the on-line phase, the required business application task [18] has been identified from the service repository and executed if it is available. In the absence of required service, the process of service discovery has been initiated to find out the appropriate services. Such scenario of discovering on-line services sometimes may leads to improper service selection. Another problem is the security and the management of the proposed system with respect to the distributed and heterogeneous environments.

Han and Sim [19] have implemented a system called Cloud Service Discovery System (CSDS) with cloud ontology for enhancing the performance of cloud service discovery. In CSDS, a search engine was designed with the software agent to find out the information sources, to simplify the users' work by omitting the unwanted surfing with to many web sites. The relevance of web-page is determined by adopting Evidence Phrases (EP), counting the 
frequencies of EP, and considering the nearness among keywords. Finally, the agent consults cloud ontology to find out the related services from the multiple cloud systems.

Karim et al. [20] proposed a novel method for Quality of Service (QoS) mapping in which a set of rules has been used to map QoS specifications and guaranteed together in the cloud. To overcome the complexity, the Analytic Hierarchy Process (AHP) has been used to perform the hierarchical analysis of the customer preferences. After that, the requirements are matched with their mapping rules to find out the possible solutions with their ranking. AHP has also led to specify QoS weights to rank and select candidate services. Finally, the authors stated the broker based service selection and ranking process as their future work.

\subsection{Cloud Service Composition for Delivery}

Service composition is a design principle [21] of service-orientation paradigm, which persuades and reuses the services in multiple solutions of composed services. Cloud computing presents an efficient, on-demand and scalable way to compose the resources of various types such as network, hardware and software. The various research efforts with respect to our broker based service discovery are discussed in this section. The broker plays a vital role in the service composition phase on behalf of the consumer. These are the software components, designed and developed to reinforce cloud resource management [22] and finally deliver the combined services to the consumer.

Sim [23] introduced an agent based paradigm for managing cloud resources. They developed a search engine called Cloudle to perform a composition of services in the cloud. In the proposed architecture, multiple cloud providers are able to record the details of their services available in a database called Cloudle, which was built and managed by the crawlers. The consumers enter their requirements in the form of queries by using the given web interface and forward them to the Service Discovery Agents (SDA) of Cloudle. The SDA refers to the cloud ontology which was constructed by the authors, and performs the similarity reasoning to de- termine the level of matching with respect to consumer's requirements. The SDA also uses service rating module, where the services provided by each provider are rated according to the similarity between the functional and technical specifications of the service provider and consumer. So, the authors tried to list out the needed services which are best fitted with the requirements posted by the consumer. The difficulty here is the construction of ontology for the user's requirements. It sometimes produces irrelevant service identification due to the lack of consumer's knowledge in the area of service identification. For example, the word apple will result in a list of fruits and the products from apple, etc.

From the cloud computing perspective, the author's contribution accounted the idea of applying agent based paradigm for automating service composition and inclusion of cloud commerce for supporting service delivery. In a federated cloud environment, if the raised requirement is not supported by the respective provider, one of the main functions of a broker is to compose the services in order to fulfill the posted need, which is called service composition [24] and is categorized into (i) Horizontal composition - which deals with combination and integration of heterogeneous service storage, computing and others, and (ii) Vertical service composition - evolves with homogeneous services such as focusing of services related to data centers alone.

Octavio and Sim [25] designed an agent to compose services from federated cloud. The agents can successfully compose services to satisfy service requirements, autonomously select the services based on dynamic fees, effectively cope with constantly changing consumer's needs that trigger updates and compose the services from multiple clouds, even with incomplete information about cloud participants. But, the deployment of the developed agent for the framework must be modified to support the multi agent interaction for the strengthening of service composition process. So, they [25] attempted a multiagent approach for cloud service composition with additional information which consists of: (i) Service ontology - for representing the services with the requirements, (ii) Directory - contains a list of available service provider agents, (iii) Consumer Agent - respon- 
sible for submitting consumer interest to broker agents, (iv) Resource Agent - orchestrates a semantic web service, (v) Semantic web service - mapping of service definition to ontology, (vi) Service Provider Agent - responsible for holding and coordinating the resource agents, (vii) Broker Agent - an intermediary between consumer and cloud provider for simplifying the task of consumer. The idea behind the proposed architecture is to provide service composition in a decentralized manner, i.e no agent is dominant over the others and a resource agent can be dynamically added without affecting the service composition process. This study helped us to design our broker with the independent decision making capabilities.

Zou et al. [26] addressed the problem of service composition in multiple federated cloud environments. The authors proposed their work which minimizes the number of clouds into a smaller group for the effectiveness of service composition. The idea was to convert this problem to a set-covering model, and find a sub-optimal cloud combination solution using an approximation algorithm, while using Artificial Intelligence (AI) planning to compose services. More specifically, the models had multiple cloud service bases as a tree and used an approximation algorithm to optimize cloud selection, while employing an AI planning system for service composition. With this paper, we have the idea to construct our broker with the AI techniques such as reasoning and learning from the situation. Also, the broker can function as per its individual thinking.

Chen and Paik [27] developed a service composition approach by exploiting the Global Social Service Network (GSSN) to assist higher-quality service composition. It is designed to perform the following: (i) the quality services are interlinked to create the relationships between them, (ii) achieve the search space reduction by applying investigation among the services. The authors proposed quality-driven workflow-search algorithm for the identification of quality links in order to provide the services with minimal cost for the end-users. But, the proposed system has two issues: (i) Failed to perform the dynamic adaptation of customer preferences, (ii) There is no possibility to concentrate on the customer's feedback.
$\mathrm{Yu}$ and Bouguettaya [28] proposed a system called service skyline for consideration of a specific set of service vendors. The main underlying idea of their work is reduction of search space which has been achieved through two well-developed algorithms namely, One Pass Algorithm (OPA) and Dual Progressive Algorithm (DPA). The algorithm OPA examines the service execution plans and saves the best solutions. The researchers have also applied some improvements on OPA for decreasing the processing time and space consumption. The second algorithm, namely DPA is based on the progressive examination of service execution plans that are sorted in ascending order of its score and progressive results. A linear approach has also been adapted to design a bottom-up algorithm to address the expensive computational costs of DPA for an increasing number of services. Table 1 summarizes the possible research efforts in the area of cloud service discovery and composition for the cloud user's consumption.

We have discussed various research highlights in the phases of cloud life cycle with respect to the need of broker based solution. From the perspective of consumer, a broker must be clever and perform the actions with or without consumer's guidance. Hence, the traits of the broker must be improved. The literature mostly provides basic capabilities and action list for the functions of the broker towards fulfilling various qualities of service parameters, certain challenging issues for the broker based cloud still exist. All those were discussed in the above section with appropriate comments. Some of the promising research works and their limitations are listed in the following Table 2.

\section{Proposed Architecture with Cloud Broker}

In this section, we introduce and justify the need of a cloud broker [29] for improving the service discovery and provisioning of cloud services for the cloud user. The proposed broker offers various value-added services on-behalf of cloud users and providers. The inclusion of broker in the cloud model can be treated as service of cloud called Software-as-a-Service (SaaS) and deemed as Cloud Broker. Accordingly, a cloud 
Table 1. Cloud service discovery and composition - research efforts and outcomes.

\begin{tabular}{|c|c|c|c|}
\hline $\begin{array}{c}\text { S. } \\
\text { No }\end{array}$ & Contributor(s) & Underlying Focus & Outcome \\
\hline 1 & Peng [7] & $\begin{array}{l}\text { Reduction of search space for service } \\
\text { discovery. }\end{array}$ & $\begin{array}{l}\text { Reduction of search space for cloud service } \\
\text { discovery using support vector machine and } \\
\text { service clustering. }\end{array}$ \\
\hline 2 & $\begin{array}{l}\text { Kang and Sim } \\
\text { [9]-[11] }\end{array}$ & $\begin{array}{l}\text { Notion of cloud service discovery based } \\
\text { on ontology. }\end{array}$ & $\begin{array}{l}\text { Ontology construction with the aid of AI } \\
\text { based reasoning. }\end{array}$ \\
\hline 3 & $\begin{array}{l}\text { Mastroianni and } \\
\text { Papuzzo [13] }\end{array}$ & $\begin{array}{l}\text { Collective service discovery for the re- } \\
\text { duction of network bandwidth. }\end{array}$ & $\begin{array}{l}\text { Discovery of co-frequented services in a } \\
\text { specified network range. }\end{array}$ \\
\hline 4 & $\begin{array}{l}\text { Choi and Jeong } \\
{[14]}\end{array}$ & $\begin{array}{l}\text { Priority weights are calculated to perform } \\
\text { the pair wise comparison. }\end{array}$ & $\begin{array}{l}\text { A broker-based evaluation system was de- } \\
\text { veloped to incorporate the service provider, } \\
\text { service consumer and the registry. }\end{array}$ \\
\hline 5 & Ronald et al. [15] & $\begin{array}{l}\text { List out the alphabetical order of bound- } \\
\text { ary values to rank the acceptable attrib- } \\
\text { utes. }\end{array}$ & $\begin{array}{l}\text { Reflections of user preferences were } \\
\text { achieved. }\end{array}$ \\
\hline 6 & Talal et al. [16] & $\begin{array}{l}\text { Ontological based service description } \\
\text { system to analyze the variety of services } \\
\text { in the cloud. }\end{array}$ & $\begin{array}{l}\text { Development of a crawler engine with the } \\
\text { layered approach for the service discovery. }\end{array}$ \\
\hline 7 & $\begin{array}{l}\text { Souza and Rabelo } \\
{[17]}\end{array}$ & $\begin{array}{l}\text { Proposed a more effective BPM-SOA } \\
\text { integration which includes business level } \\
\text { for the service discovery arena. }\end{array}$ & $\begin{array}{l}\text { Business process logic has been introduced } \\
\text { to offer the services. }\end{array}$ \\
\hline 8 & Han and Sim [19] & $\begin{array}{l}\text { Ontological construction based system } \\
\text { for the discovery of cloud service. }\end{array}$ & $\begin{array}{l}\text { Implemented an agent based approach with } \\
\text { reasoning process. }\end{array}$ \\
\hline 9 & Karim et al. [20] & $\begin{array}{l}\text { QoS based system to focus the service } \\
\text { selection and ranking for delivery. }\end{array}$ & $\begin{array}{l}\text { Hierarchical analysis achieved through the } \\
\text { AHP decision making. }\end{array}$ \\
\hline 10 & $\operatorname{Sim}[23]$ & $\begin{array}{l}\text { Improvement of service discovery } \\
\text { through the software agent 'Cloudle'. }\end{array}$ & $\begin{array}{l}\text { Similar services are selected from the feder- } \\
\text { ated clouds. }\end{array}$ \\
\hline 11 & $\begin{array}{l}\text { Octavio and Sim } \\
{[24]}\end{array}$ & $\begin{array}{l}\text { Multiagent approach for the service dis- } \\
\text { covery is attempted. }\end{array}$ & $\begin{array}{l}\text { Decentralized service composition is } \\
\text { achieved. }\end{array}$ \\
\hline 12 & $\begin{array}{l}\text { Octavio and Sim } \\
{[25]}\end{array}$ & $\begin{array}{l}\text { Attempted for multiple service composi- } \\
\text { tion with the aid of multiagent approach. }\end{array}$ & Autonomous service selection is achieved. \\
\hline 13 & Zou et al. [26] & $\begin{array}{l}\text { Introduced the set covering model, to find } \\
\text { the optimal cloud combination solution } \\
\text { using an approximation algorithm. }\end{array}$ & $\begin{array}{l}\text { Optimized cloud selection by minimizing } \\
\text { the number of clouds involved in a service } \\
\text { composition sequence. }\end{array}$ \\
\hline 14 & $\begin{array}{l}\text { Chen and Paik } \\
\text { [27] }\end{array}$ & $\begin{array}{l}\text { Constructed the Global Social Service } \\
\text { Network to perform the cloud service } \\
\text { composition. }\end{array}$ & $\begin{array}{l}\text { Quality of service composition through the } \\
\text { social links. }\end{array}$ \\
\hline 15 & $\begin{array}{l}\text { Yu and Bouguet- } \\
\text { taya [28] }\end{array}$ & $\begin{array}{l}\text { A service skyline was developed with a } \\
\text { specific set of service vendors to obtain } \\
\text { the best set of single services for service } \\
\text { composition. }\end{array}$ & Search space reduction is achieved. \\
\hline
\end{tabular}

broker is a third party business entity placed in between the consumer and provider to act as an intermediary. It assists the consumers to define their technical requirements and evaluate infrastructure capabilities, security policies and it also the best service offered by the provider. Accordingly, the broker gathers the customer requirements in the perspective of work process, provisioning categories, cost factor. After the requirements gathering, the broker identifies and prepares the list of recommended cloud providers for the customer interaction and usage. Though the cloud broker exists as an intermediary between cloud provider and cloud 
Table 2. Broker based research efforts and limitations.

\begin{tabular}{|c|l|l|c|l|l|}
\hline $\begin{array}{c}\text { S. } \\
\text { No }\end{array}$ & Contributor(s) & $\begin{array}{c}\text { Approach/ } \\
\text { Methodology }\end{array}$ & $\begin{array}{c}\text { Service Discovery } \\
\text { in Cloud }\end{array}$ & $\begin{array}{c}\text { Service } \\
\text { Provisioning }\end{array}$ & \multicolumn{1}{|c|}{$\begin{array}{c}\text { Shortfalls in the } \\
\text { Proposed Model }\end{array}$} \\
\hline 1 & $\begin{array}{l}\text { Kang and Sim } \\
{[9]-[11]}\end{array}$ & $\begin{array}{l}\text { Test bed based } \\
\text { model }\end{array}$ & Available & Not Available & $\begin{array}{l}\text { Need of both connection pro- } \\
\text { cedure and cloud ontology. }\end{array}$ \\
\hline 2 & $\begin{array}{l}\text { Choi and Jeong } \\
{[14]}\end{array}$ & $\begin{array}{l}\text { Simulation } \\
\text { Model }\end{array}$ & Available & Not Available & $\begin{array}{l}\text { Context based service selec- } \\
\text { tion. }\end{array}$ \\
\hline 3 & Talal et al. $[16]$ & $\begin{array}{l}\text { Architecture } \\
\text { Model }\end{array}$ & Available & Not Available & $\begin{array}{l}\text { WSDL-Standard is not suit- } \\
\text { able for cloud service descrip- } \\
\text { tion. }\end{array}$ \\
\hline 4 & $\begin{array}{l}\text { Han and Sim } \\
{[19]}\end{array}$ & Prototype model \\
5 & $\begin{array}{l}\text { Sim [23] } \\
\text { Test bed/Model }\end{array}$ & Available & Not Available & $\begin{array}{l}\text { No independent action in the } \\
\text { service discovery. }\end{array}$ \\
\hline 6 & $\begin{array}{l}\text { Octavio and Sim } \\
{[24],[25]}\end{array}$ & $\begin{array}{l}\text { Architecture } \\
\text { Model }\end{array}$ & Available & Available & $\begin{array}{l}\text { Large number of agents' } \\
\text { interaction may increase users } \\
\text { waiting time. }\end{array}$ \\
\hline
\end{tabular}

consumer, and it offers various value added services on behalf of both parties, it is more appropriate to build the broker with the principle of decision making capabilities. Such kind of capabilities [30] facilitates appropriate reasoning and decision making power for the broker.

\subsection{Proposed Cloud Broker for Cloud Service Model}

In common, cloud computing is understood as a model of web services which are offered by the traditional Internet computing. The user may find the required service from the Internet, through the middleware like browser. It just shows the related terms according to the phrase typed by the user in the client machine. Also, the existing cloud model uses the interface to get the requirements from the user side. Then the process of service discovery is listed out as the reference for the user to go for further processing (i.e consumption of services). Hence, it has been decided to take care of the user requirements, carefully perform the service discovery and provisioning, without much more confusion. From this idea, the layer of cloud broker has been introduced in the existing cloud model, as shown in Figure 2. The proposed broker performs functionalities such as requirement gathering, service discovery and service composition for the provisioning.

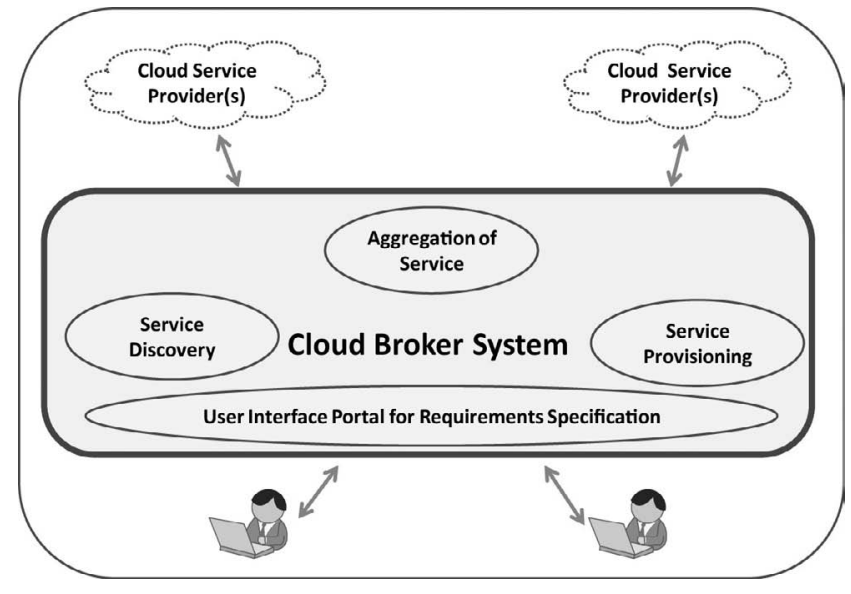

Figure 2. Proposed system with the inclusion of cloud broker.

\subsubsection{User Interface for Requirement Specification}

The success of service discovery solely depends on understanding the requirements specified by the cloud user. To achieve this, a user interface has been introduced as part of our broker architecture. A portal may be a Web service which can be executed through the Internet. A suitable front-end prototype with possible user operations have been planned and resulted as User Interface Portal for Requirements Specification (UIPRS). 


\subsubsection{Service Discovery}

The service discovery part of the broker has been constructed with the aid of reasoning and decision making principles used in Artificial Intelligence (AI) techniques. With the incorporation of such techniques to the broker, suitable services have been identified against the posted requirement. The discovery is also constrained by technical specification, budgetary and security policies of the services. Assume that there are set of services, $S_{1}, S_{2}, S_{3}$ which are available with the different service providers, $S P_{1}, S P_{2}$, $S P_{3}$. After gathering the requirements through UIPRS, the broker formulates the description of services with the aid of reasoning and decision making capabilities found in AI techniques. All descriptions have been carefully analyzed and the required details have been chosen to form the heap tree for ranking the services Figure 3.

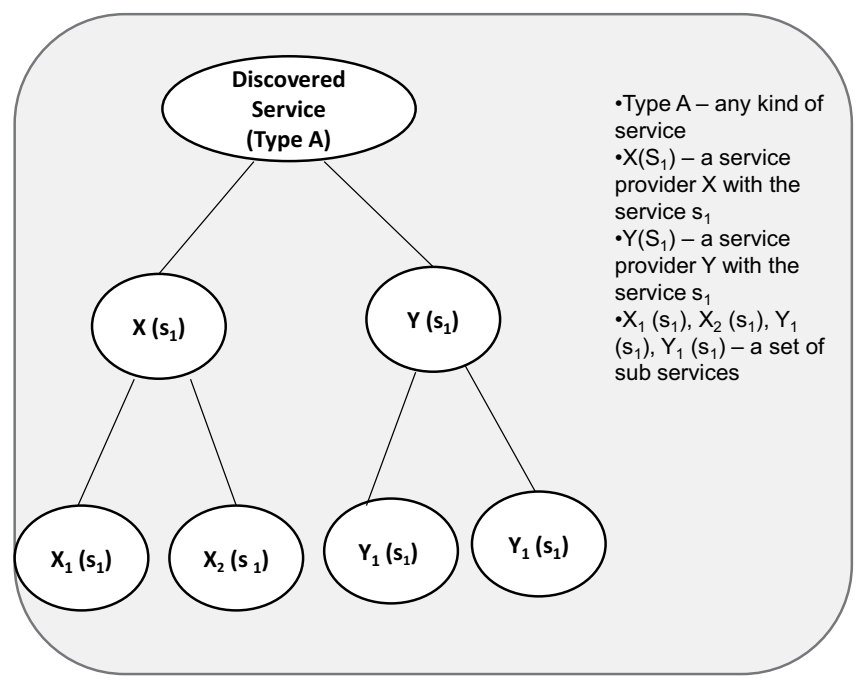

Figure 3. A Heap Tree based service ranking by Cloud Broker.

\subsubsection{Aggregation and Cloud Service Delivery}

In this phase, broker aggregates the discovered services and rank them according to the customer preferences. Normally, aggregation meant the accumulation of services as a composite one for customer usage. The introduced broker performs value added services such as service ranking against QoS specification, etc.

\section{Conclusion}

This paper presents a broker based cloud service model for the discovery of services as per the consumer requirements. An extensive survey has also been presented in the areas such as service discovery and composition. A cloud service model with the inclusion of cloud broker and its desirable features are also discussed. As a future work, our proposal can further be extended towards an intelligent cloud broker that suits for the federated cloud environment for the improved provisioning services.

\section{References}

[1] R. Buyya et al., "Cloud Computing - Principles and Paradigms", John Wiley and Sons, 2011. http://dx.doi.org/10.1002/9780470940105

[2] P. Mell and T. Grance, The NIST Definition of Cloud Computing, 2011.

[3] B. P. Rimal et al., "A Taxonomy and Survey of Cloud Computing Systems", in Proceedings of the Fifth International Joint Conference on INC, IMS and IDC, pp. 44-51, 2009. http://dx.doi.org/10.1109/ncm.2009.218

[4] F. Hu et al., "A Review on Cloud Computing: Design Challenges in Architecture and Security", Journal of Computing and Information Technology, vol.19, no.1, pp. 25-55, 2011. http://dx.doi.org/10.2498/cit.1001864

[5] K-R Lee et al., "A Hierarchical Scheduling Strategy for the Composition Services Architecture Based on Cloud Computing", in Proceedings of the Second International Conference on Next Generation Information Technology, pp.163$169,2011$.

[6] H. Dong and F. K. Hussain, "A Service Concept Recommendation System for Enhancing the Dependability of Semantic Service Matchmakers in the Service Ecosystem Environment", Journal of Network and Computer Applications, vol. 34, no. 2, pp.619-631, 2011. http://dx.doi.org/10.1016/j.jnca.2010.11.010

[7] Y. Peng, "Rapid Service Discovery based on Clustering", in Proceedings of the International Conference on Medical Physics and Biomedical Engineering, vol. 33, pp. 195-200, 2012. http://dx.doi.org/10.1016/j.phpro.2012.05.050

[8] A. Mccallum et al., "Efficient Clustering of High-Dimensional Data Sets with Application to Reference Matching", in Proceedings of the Sixth $A C M$ SIGKDD, International Conference on 
Knowledge Discovery and Data Mining, pp.169$178,2000$.

http://dx.doi.org/10.1145/347090.347123

[9] J. Kang and K. M. Sim, "Cloudle: An Agentbased Cloud Search Engine that Consults a Cloud Ontology", in Proceedings of the International Conference on Cloud Computing and Virtualization (CCV), 2010.

[10] J. Kang and K. M. Sim, "A Cloud Portal with a Cloud Service Search Engine", in Proceedings of the International Conference on Information Intelligent Computing, pp.1-8, 2011.

[11] J. Kang and K. M. Sim, "Towards Agents and Ontology for Cloud Service Discovery", in Proceedings of the International Conference on Cyber-enabled Distributed Computing and Knowledge Discovery, pp. 483-490, 2011. http://dx.doi.org/10.1109/cyberc.2011.84

[12] T. Uchibayashi et al., "Towards a Cloud Ontology Clustering Mechanism to Enhance IaaS Service Discovery and Selection", Springer International Publishing Switzerland, pp. 545-556, 2015. http://dx.doi.org/10.1007/978-3-319-21404-7_40

[13] C. Mastroianni and G. Papuzzo, "A Self-organizing P2P Framework for Collective Service Discovery", Journal of Network and Computer Applications, vol. 39, pp. 214-222, 2014. http://dx.doi.org/10.1016/j.jnca.2013.07.002

[14] C. R. Choi and H. Y. Jeong, "A Broker-based Quality Evaluation System for Service Selection According to the QOS Preferences of Users", Information Sciences, vol.277, pp. 553-566, 2014. http://dx.doi.org/10.1016/j.ins.2014.02.141

[15] R. Ronald et al., "Using a Web Personal Evaluation Tool-Pet for Lexicographic Multi-Criteria Service Selection", Knowledge Based System, vol. 24, no. 7, pp. 929-942, 2011. http://dx.doi.org/10.1016/j.knosys.2011.02.004

[16] H.Talal et al., "CSCE: A Crawler Engine for Cloud Services Discovery on the World Wide Web", in Proceedings of the IEEE 20th International Conference on Web Services, pp. 443-450, 2013.

[17] A. P. de Souza and R. J. Rabelo, "A Model for Dynamic Services Discovery over Largely Distributed Providers Based on QOS and Business Processes Contexts", in Proceedings of the IEEE World Congress on Services, pp. 347-354, 2011.

[18] S. Marston et al., "Cloud computing - The Business Perspective", Decision Support Systems, vol.51, no.1, pp.176-189, 2011. http://dx.doi.org/10.1016/j.dss.2010.12.006

[19] T. Han and K. M. Sim, "An Ontology-enhanced Cloud Service Discovery System", in Proceedings of the International Multi Conference of Engineers and Computer Scientist, 2010.
[20] R. Karim et al., "An End-to-end QOS Mapping Approach for Cloud Service Selection in Services", in Proceedings of the Ninth IEEE World Congress on Services, pp. 341-348, 2013. http://dx.doi.org/10.1109/services.2013.71

[21] A. Jula et al., "Cloud Computing Service Composition: A Systematic Literature Review", Expert Systems with Applications, vol. 41, no. 8, pp. 3809-3824, 2014.

http://dx.doi.org/10.1016/j.eswa.2013.12.017

[22] A. Beloglazov et al., "Energy-aware Resource Allocation Heuristics for Efficient Management of Data Centers for Cloud Computing", Future Generation Computer Systems, vol. 28, no. 5, pp. 755-758, 2012.

http://dx.doi.org/10.1016/j.future.2011.04.017

[23] K. M. Sim, "Agent-based Cloud Computing", IEEE Transactions on Services Computing, vol. 5, no. 4, pp. 564-577, 2012. http://dx.doi.org/10.1109/TSC.2011.52

[24] J. Octavio Gutierrez-Garcia and K. M. Sim, "Agent-based Service Composition in Cloud Computing", in Proceedings of the Conference on Grid and Distributed Computing, pp. 1-10, 2010. http://dx.doi.org/10.1007/978-3-642-17625-8_1

[25] J. Octavio Gutierrez-Garcia and K. M. Sim, "Agent-based Cloud Service Composition", Applied Intelligence - The International Journal of Artificial Intelligence, Neural Networks and Complex Problem Solving Technologies. Vol. 22, no. 2, pp. 436-464, 2013.

[26] G. Zou et al., "AI Planning and Combinatorial Optimization for Web Service Composition in Cloud Computing", in Proceedings of the International Conference on Cloud Computing and Virtualization, 2010. http://dx.doi.org/10.5176/978-981-08-5837-7_166

[27] W. Chen and I. Paik, "Toward Better Quality of Service Composition Based on a Global Social Service Network", IEEE Transactions on Parallel and Distributed Systems, vol. 26, no. 5, pp. 1466-1476, 2014.

http://dx.doi.org/10.1109/TPDS.2014.2320748

[28] Q. Yu and A. Bouguettaya, "Efficient Service Skyline Computation for Composite Service Selection", IEEE Transactions on Knowledge and Data Engineering, vol. 25, no. 4, pp. 776-789, 2013. http://dx.doi.org/10.1109/TKDE.2011.268

[29] M. Guzek et al., "Cloud Brokering: Current Practices and Upcoming Challenges", IEEE Cloud Computing, vol. 2, no. 2, 2015.

[30] S. G. Grivas et al., "Cloud Broker: Bringing Intelligence in to the Cloud an Event-based Approach", in Proceedings of the Third IEEE International Conference on Cloud Computing, pp. 544-545, 2010. 
Received: August, 2015

Revised: November, 2015

Accepted: November, 2015

Contact addresses:

Rajganesh Nagarajan

Department of Information Technology

A.V.C. College of Engineering

Mayiladuthurai - 609305

Tamilnadu

India

e-mail: anuvarajganesh@gmail.com

Ramkumar Thirunavukarasu

School of Information Technology and Engineering

VIT University

Vellore -632014

Tamilnadu

India

e-mail: ramooad@yahoo.com

RAJGANESH NAGARAJAN is currently working as an Assistant Professor in the Department of Information Technology, A.V.C College of Engineering, Tamilnadu, India. He is presently pursuing his $\mathrm{PhD}$ degree at the Faculty of Information and Communication Engineering, Anna University, Chennai. His research interests include efficient discovery of cloud services from the federated cloud environment, broker based service provisioning. He has presented his thoughts in various national/ international journals and conferences.

RAMKUMAR ThiRUnavuKarasu is working as an Associate Professor in School of Information Technology and Engineering, VIT University, Vellore, Tamilnadu, India. He has received his $\mathrm{PhD}$ degree in Computer Science from Anna University, Chennai, India. His area of specialization includes knowledge discovery from multiple databases and big data analytics with machine learning. He has contributed numerous top notching publications in various SCI journals. Presently, he is guiding four research scholars in the areas of cloud brokerage, secondary structure proteins, health informatics and E-Learning. 